\title{
Recurrent severe hyperandrogenism during pregnancy: a case report
}

\author{
H B Holt, S Medbak, D Kirk, R Guirgis, I Hughes, M H Cummings, D R Meeking
}

J Clin Pathol 2005;58:439-442. doi: 10.1136/icp.2004.018382

This report describes the case of a 28 year old woman with virilisation occurring in two successive pregnancies. Recurrent maternal virilisation is rare (seven previous reports) and this case is unique in its severity. Differential diagnoses include ovarian disease and fetal aromatase deficiency. New techniques to exclude a fetal cause were used in this case. This patient presented during the third trimester of her first pregnancy with rapid onset of hirsuitism, increased musculature, and deepening voice. A blood hormone profile revealed significant hyperandrogenism (testosterone, $72.4 \mathrm{nmol} /$ litre; normal range, 0.5-3.0). She delivered a normal boy and maternal androgen concentrations returned rapidly to normal (testosterone, $0.8 \mathrm{nmol} /$ litre). She presented two years later, during her second pregnancy, with similar symptoms and biochemistry (testosterone, $47.5 \mathrm{nmol} /$ litre). Again, she delivered a healthy normal boy and androgens returned immediately to normal (serum testosterone, $2.0 \mathrm{nmol} /$ litre). Ultrasonography revealed no evidence of ovarian (or adrenal) masses in either pregnancy. Umbilical cord venous blood sampling and placental assays revealed no evidence of fetal aromatase deficiency. Recurrent hyperandrogenism during pregnancy is rare. Ovarian luteoma rarely recurs and hyperreactio luteinalis does not lead to such pronounced androgen concentrations. Therefore, this patient has a unique ovarian condition that could be harmful to offspring and mother.

$\mathrm{V}$ irilisation during pregnancy is rare and there are few reported cases of recurrence in a subsequent pregnancy. Potential causes may be ovarian, fetal, or adrenal, although there are no reports of adrenal pathology being implicated in the aetiology of recurrent gestational virilisation. Ovarian causes of virilisation include primary malignancy, polycystic ovarian syndrome (PCOS), luteoma, and hyperreactio luteinalis (HL). The last two conditions are associated with large ovarian masses (with androgen production in proportion to the size of the ovarian mass), and rarely recur. ${ }^{1}$ Virilisation associated with PCOS is normally mild. ${ }^{2}$ Fetal aromatase deficiency (FAD) results from a genetic defect in the fetus, and can lead to maternal virilisation as a result of absent aromatase activity in the placenta. We have used novel techniques to exclude this diagnosis.

"Virilisation during pregnancy is rare and there are few reported cases of recurrence in a subsequent pregnancy"

There are seven previously reported cases of recurrent virilisation of pregnancy. This eighth case appears to be unique in its severity and perhaps its aetiology.

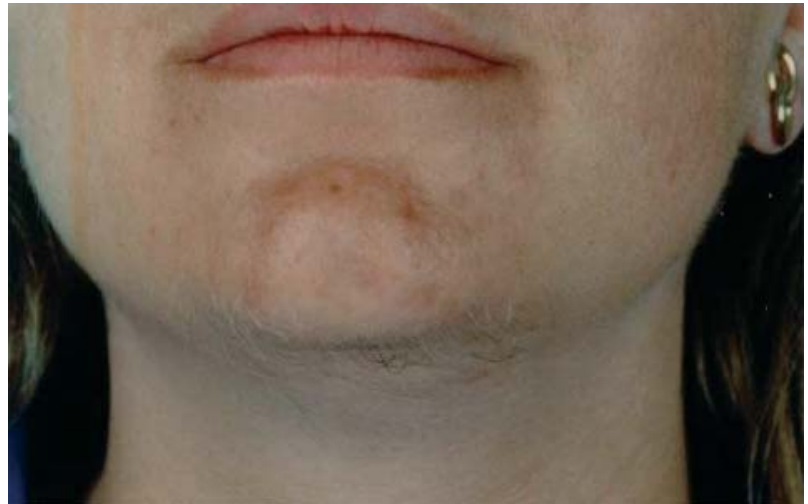

Figure 1 Pronounced facial hirsuitism and acne. The patient gave her permission for this photograph to be reproduced.

\section{CASE REPORT}

A 25 year old white woman presented at 37 weeks of gestation complaining of excess hair growth on her face and abdomen and a deepening voice of two months' duration. The pregnancy was otherwise normal. She had no other past medical history and her only medication was folic acid. The pregnancy was planned and she became pregnant in her second menstrual cycle after discontinuation of the oral contraceptive pill. Her menstrual cycle had been regular before starting oral contraception. Examination revealed pronounced facial hair and acne (fig 1), with increased hair growth on her limbs and abdomen. Her voice was deep and she had increased upper body musculature. Blood investigations revealed a serum testosterone of $72.4 \mathrm{nmol} /$ litre, sex hormone binding globulin (SHBG) of $570 \mathrm{nmol} /$ litre, androstenedione of $156 \mathrm{nmol} /$ litre, and dihydroepiandrosterone sulfate (DHEAS) of $2.8 \mu \mathrm{mol} /$ litre. Labour was induced at 38 weeks and she delivered a healthy male infant vaginally. The baby had no signs of excess androgen exposure and possessed normal external genitalia.

A pelvic ultrasound scan was performed four weeks postpartum and showed moderately enlarged ovaries containing multiple small cysts but no discrete masses. Her androgen profile rapidly returned to normal (testosterone, $0.8 \mathrm{nmol} /$ litre at three weeks postpartum). Her symptoms improved over the following weeks with dramatic resolution of her hirsuitism, although mild facial hair growth remained. Her deep voice resolved.

She remained asymptomatic with normal androgen profiles for two years until she re-presented while planning

Abbreviations: DHEAS, dihydroepiandrosterone sulfate; FAD, fetal aromatase deficiency; hCG, human chorionic gonadotrophin; $\mathrm{HL}$, hyperreactio luteinalis; PCOS, polycystic ovarian syndrome; SHBG, sex hormone binding globulin 
Table 1 Androgen profiles during the second pregnancy

\begin{tabular}{|c|c|c|c|c|c|c|c|c|c|c|}
\hline Androgen & Pre-preg & 1 month & 2 months & 3 months & 4 months & 5 months & 6 months & 7 months & 8 months & Postnatal \\
\hline $\begin{array}{l}\text { Testosterone (nmol/I) } \\
\text { Oestradiol (pmol/l) } \\
\text { Androstenedione (nmol/l) } \\
\text { DHEAS (nmol/l) }\end{array}$ & 1.4 & $\begin{array}{l}4.5 \\
1400 \\
18.1\end{array}$ & $\begin{array}{l}12.2 \\
32.5\end{array}$ & $\begin{array}{l}21.8 \\
34900 \\
50.0 \\
4.3\end{array}$ & $\begin{array}{l}22.8 \\
48300 \\
72.0 \\
3.2\end{array}$ & $\begin{array}{l}20.5 \\
73900 \\
59.4 \\
5.1\end{array}$ & $\begin{array}{l}32.7 \\
108900 \\
60.0 \\
3.1\end{array}$ & $\begin{array}{l}37.2 \\
106600 \\
121.0 \\
2.9\end{array}$ & $\begin{array}{l}47.5 \\
220400 \\
115.0 \\
2.3\end{array}$ & $\begin{array}{l}2.0 \\
800 \\
5.4\end{array}$ \\
\hline
\end{tabular}

another pregnancy. Her menstrual cycle remained normal on discontinuing oral contraception. A short Synacthen test excluded congenital adrenal hyperplasia: 17-hydroxyprogesterone was $8 \mathrm{nmol} /$ litre at 30 minutes.

Within two menstrual cycles she became pregnant again, aged 28 years. She noticed a recurrence of her symptoms, with excess hair growth and a deepening voice developing from six weeks of gestation. On examination she was again found to be virilised with hirsuitism, deepening voice, and increased upper body musculature. Testosterone concentrations increased gradually as the pregnancy progressed (table 1). An ultrasound scan at 16 weeks of gestation revealed a male fetus. No pelvic or abdominal abnormality was seen. She became severely virilised during the second trimester, with worsening hirsuitism, acne, increased upper body musculature, and deepening voice. The pregnancy was otherwise uneventful and she had a normal vaginal delivery after labour was induced by prostaglandin pessary at 39 weeks of gestation. She delivered a healthy male infant with normal external genitalia. At delivery, samples of maternal and cord blood were taken. A segment of placental tissue was taken, stored in liquid nitrogen, and frozen for subsequent analysis of aromatase activity. Fetal cord blood demonstrated a fetal testosterone concentration that was significantly lower than the maternal testosterone concentration (table 2), suggesting a normal placental aromatase activity level.

Postnatally, her symptoms improved within weeks. Her voice returned to normal and the hirsuitism resolved. Three weeks postnatally, the blood hormone profile was as follows: luteinising hormone, 0.7 IU/litre; follicular stimulating hormone, $3.3 \mathrm{IU} / \mathrm{litre}$; oestradiol, $108 \mathrm{pmol} / \mathrm{litre}$; testosterone, $2.0 \mathrm{nmol} / \mathrm{litre}$ SHBG, $169 \mathrm{nmol} / \mathrm{litre}$ androstenedione, $5.4 \mathrm{nmol} /$ litre; and 17-hydroxyprogesterone, $<3.0 \mathrm{nmol} /$ litre. A repeat pelvic ultrasound scan at five weeks revealed normal sized ovaries containing multiple small cysts and no ovarian masses. Androgen concentrations were subsequently checked weekly for a four week period to determine whether there was a correlation with gonadotrophin values (table 3 ). Androgens remained within the normal range throughout.

\section{ANDROGEN ASSAYS}

Testosterone in the first pregnancy was analysed on an ASC 180 analyser (Bayer Diagnostics Leverkusen, Germany) by chemiluminescent immunoassay with an interassay precision of $10.5 \%$ at $1.3 \mathrm{nmol} /$ litre, $8.3 \%$ at $17.0 \mathrm{nmol} /$ litre, and $6.9 \%$ at $33.2 \mathrm{nmol} /$ litre. For the second pregnancy testosterone,

Table 2 Maternal and fetal blood at delivery

\begin{tabular}{lll}
\hline & Maternal blood & Fetal blood \\
\hline Testosterone & $47.5 \mathrm{nmol} / \mathrm{l}$ & $4.8 \mathrm{nmol} / \mathrm{I}$ \\
DHEAS & $2.3 \mathrm{nmol} / \mathrm{l}$ & \\
SHBG & $671 \mathrm{nmol} / /$ & \\
Androstenedione & $115 \mathrm{nmol} / \mathrm{l}$ & $13.8 \mathrm{nmol} / \mathrm{I}$ \\
Oestradiol & $220000 \mathrm{pmol} / \mathrm{l}$ & \\
\hline
\end{tabular}

DHEAS, dihydroepiandrosterone sulfate; SHBG, sex hormone binding globulin. gonadotrophins, prolactin, and progesterone were analysed by chemiluminescent immunoassay on an ARCHITECT analyser (Abbott Diagnostics, Maidenhead, Berkshire, UK). Interassay precision for testosterone on this analyser was $8.2 \%$ at $1.5 \mathrm{nmol} /$ litre, $7.8 \%$ at $3.0 \mathrm{nmol} /$ litre, and $7.1 \%$ at $31.5 \mathrm{nmol} /$ litre.

Androstenedione was measured by radioimmunoassay using a kit from Diagnostic Systems Ltd (Webster, Texas, USA). This has an interassay precision of $6.3 \%$ at $2.2 \mathrm{nmol} /$ litre, $4.8 \%$ at $7.2 \mathrm{nmol} /$ litre, and $7.0 \%$ at $22.5 \mathrm{nmol} / \mathrm{litre}$. High value samples were diluted into the working range of the kit using the zero calibrator supplied by the manufacturer.

DHEAS and SHBG were analysed by chemiluminescent immunoassay on an IMMUNOLITE analyser (Diagnostic Products Corporation, Los Angeles, California, USA). The interassay precision for DHEAS was $13 \%$ at $1.4 \mu \mathrm{mol} / \mathrm{litre}$, $9.3 \%$ at $5.8 \mu \mathrm{mol} /$ litre, and $7.9 \%$ at $17.9 \mu \mathrm{mol} /$ litre. For SHBG the interassay precision was $4 \%$ at $4.7 \mathrm{nmol} /$ litre, $5.2 \%$ at $63 \mathrm{nmol} /$ litre, and $6.6 \%$ at $80 \mathrm{nmol} /$ litre. The samples were diluted $1 / 10$ before analysis with sample diluent supplied with the kit.

Oestradiol was analysed by fluorometric immunoassay on an AUTODELFIA analyser (Perkin Elmer Life Sciences, Foster City, California, USA). This method has an interassay precision of $4.5 \%$ at $240 \mathrm{pmol} / \mathrm{litre}, 3.4 \%$ at $897 \mathrm{pmol} / \mathrm{litre}$, and $4.7 \%$ at $2600 \mathrm{pmol} /$ litre. The pregnancy samples were diluted to within the working range of the kit with the zero calibrator.

As a guide to the concentrations that are found in normal pregnancy, DHEAS, androstenedione, testosterone, and SHBG were measured in 15 women at 16-20 weeks of gestation (table 4).

\section{AROMATASE ASSAY}

Previously frozen placental tissue was homogenised in four volumes of ice cold phosphate buffered saline. The resulting homogenate was centrifuged at $1000 \times g$ for 15 minutes at $4^{\circ} \mathrm{C}$ and the protein content of the supernatant measured using a modified Lowry method. ${ }^{3}$ Aromatase activity was determined using a tritiated water assay based on a method previously reported for genital skin fibroblasts. ${ }^{4}$ Briefly, $10 \mu \mathrm{l}$ of supernatant was added to $1 \mathrm{ml}$ phosphate buffered saline containing NAD,NADPH (1mM) and progesterone (5uM). Tritiated $\beta$ androstenedione (NET $926250 \mu \mathrm{Ci}$ ) was added as substrate to provide approximately 70000 disintegrations/ minute and incubated for two hours at $37^{\circ} \mathrm{C}$. The reaction was stopped by the addition of unlabelled androstenedione and $2 \mathrm{ml}$ of chloroform. Sealed tubes were gently agitated for two hours. A $200 \mu \mathrm{l}$ sample of the aqueous layer was added to $4 \mathrm{ml}$ scintillant and the tritiated water was counted on a Canberra Packard 2500TR. The analysis was performed in triplicate; results were expressed as $\mathrm{fmol} / \mathrm{mg}$ protein/hour.

\section{Results}

Placental aromatase activity was in excess of $500 \mathrm{fmol} / \mathrm{mg}$ protein/hour. Mean (SD) values in genital skin fibroblasts were 215 (33.9) fmol/mg protein/hour $(\mathrm{n}=20$ (2)). This 
Table 3 Steroid profiles over the menstrual cycle

\begin{tabular}{|c|c|c|c|c|c|c|c|c|c|}
\hline $\begin{array}{l}\text { Day of } \\
\text { cycle }\end{array}$ & $\begin{array}{l}\text { LH } \\
\text { (IU/I) }\end{array}$ & $\begin{array}{l}\text { FSH } \\
\text { (IU/I) }\end{array}$ & $\begin{array}{l}\text { Prolactin } \\
\text { (mlU/l) }\end{array}$ & $\begin{array}{l}\text { Progesterone } \\
\text { (nmol/l) }\end{array}$ & $\begin{array}{l}\text { Oestradiol } \\
\text { (pmol/l) }\end{array}$ & $\begin{array}{l}\text { Testosterone } \\
\text { (nmol/l) }\end{array}$ & $\begin{array}{l}\text { Androstenedione } \\
\text { (nmol/l) }\end{array}$ & $\begin{array}{l}\text { DHEAS } \\
(\mu \mathrm{mol} / \mathrm{I})\end{array}$ & $\begin{array}{l}\text { 17-OHP } \\
\text { (nmol/l) }\end{array}$ \\
\hline 2 & 3.9 & - & 501 & 7.5 & 174 & 1.5 & 7.9 & 5.6 & 7.2 \\
\hline 8 & 5.9 & 6.8 & 377 & 0.8 & 137 & 1.8 & 10.0 & 4.3 & 5.3 \\
\hline 15 & 6.3 & 4.7 & 386 & 0.5 & 331 & 1.6 & 8.8 & 6.3 & 4.1 \\
\hline 22 & 12.1 & 4.0 & 497 & 23.9 & 296 & 2.0 & 7.0 & 5.7 & 7.0 \\
\hline
\end{tabular}

DHEAS, dihydroepiandrosterone sulfate; FSH, follicle stimulating hormone; LH, luteinising hormone; 17-OHP, 17-hydroxyprogesterone.

result indicates that there was no evidence of aromatase deficiency in the placenta.

\section{DISCUSSION}

Recurrent maternal virilisation during pregnancy is extremely unusual. The level of androgenisation in our patient was startling, yet transient. The origin appears to be ovarian but no clear pathology was demonstrable. Several ovarian conditions can result in excessive androgen production in pregnancy. Benign lesions include luteoma and HL. These conditions are associated with large ovarian masses and were originally thought to reflect different ends of a spectrum of pathology resulting from hyper-responsiveness to human chorionic gonadotrophin (hCG). It now appears that they are distinct clinical entities, although distinguishing the two diagnoses can be difficult on clinical or histological grounds. ${ }^{5}$ Ovarian luteomas are usually solid, multinodular lesions that may be unilateral or bilateral. They occur most commonly in multiparous women of Afro-Caribbean descent and are more common in women with preexisting PCOS. Luteomas can be associated with raised androgens, although they are rarely high enough to cause virilisation and usually regress completely postpartum. There are four reported cases of recurrent luteoma associated with raised androgen concentrations. Two cases presented as ovarian masses with androgenisation as a secondary finding, and three occurred in multiparous women. The first case was of a woman with bilateral ovarian masses noted at two consecutive caesarean sections associated with raised 17-ketosteroid concentrations of $110.7 \mathrm{mg} / 24$ hours (normal range, 6-15). ${ }^{6}$ The second case was of a multigravida Afro-Caribbean woman who had bilateral luteomas diagnosed at caesarean section in consecutive pregnancies. Urinary 17-ketosteroid values were $230 \mathrm{mg} / 24$ hours, but returned to normal within 10 days after birth. ${ }^{7}$ The third case was also a multiparous Afro-Caribbean woman who presented during her first pregnancy with a serum testosterone concentration of $40.7 \mathrm{nmol} /$ litre and androstenedione of $21.8 \mathrm{nmol} /$ litre before delivery. Three months postpartum serum testosterone was $3.9 \mathrm{nmol} /$ litre and androstenedione was $11.6 \mathrm{nmol} /$ litre. In this woman, the ovarian mass was noted early in pregnancy and was not present on postpartum ultrasound scanning. An ovarian mass was not found subsequently when androgens were raised during a second pregnancy that was terminated at 12

Table 4 Normal hormone concentrations at 16 to 20 weeks of gestation

\begin{tabular}{ll}
\hline Hormone & Normal concentration \\
\hline DHEAS & $0.8-5.8 \mu \mathrm{mol} / /(2.30)$ \\
Androstenedione & $3.2-12.5 \mathrm{nmol} / /(6.7)$ \\
Testosterone & $0.8-3.3 \mathrm{nmol} / /(1.7)$ \\
SHBG & $97-476 \mathrm{nmol} / /(305)$ \\
\hline
\end{tabular}

Values are range (mean).

DHEAS, dihydroepiandrosterone sulfate; SHBG, sex hormone binding globulin. weeks. $^{8}$ A fourth case, that of a 26 year old white primigravida woman has been described. She presented during pregnancy with virilisation and raised androgen concentrations (serum testosterone, $23.2 \mathrm{nmol} /$ litre), but with no associated ovarian mass. Testosterone concentrations did not quite return to normal ( $4.5 \mathrm{nmol} /$ litre) between pregnancies, and the patient suffered with oligomenorrhoea and subfertility, suggestive of PCOS. ${ }^{9}$

These diagnoses seem unlikely in our patient. She is white, slim, presented as a primigravida, and had no ovarian masses. In addition, her androgen concentrations were much higher than those previously reported.

HL is commonly a cystic, bilateral ovarian condition. It typically occurs in white primigravida women, and is associated with conditions that involve raised hCG values, such as multiple gestation and molar pregnancies. Ovarian hyperstimulation syndrome, which may occur after induction of ovulation with hCG, is thought to be an iatrogenic variant of this condition. HL can occasionally recur in subsequent pregnancies, but raised androgen values and androgenisation are only seen in $15 \%$ of cases. ${ }^{1}$ There is only one case report of recurrent HL associated with raised androgen concentrations. ${ }^{10}$ Where androgenisation does occur in this condition it is in proportion to the size of the ovarian lesions. Because our patient had no ovarian lesion but extremely high androgen concentrations this diagnosis seems very unlikely.

PCOS may worsen during pregnancy, but in the only reported case associated with recurrent virilisation testosterone concentrations were moderate ( $18.3 \mathrm{nmol} / \mathrm{litre}){ }^{2}$ Our patient showed no additional features of PCOS.

"Fetal aromatase deficiency was excluded in our patient by the normal cord androgens, the absence of low maternal oestrogen values, and the normal placental aromatase activity"

FAD is a recently described cause of recurrent virilisation in pregnant women and there is one case report of two affected siblings. ${ }^{11}$ Aromatase is a cytochrome p450 enzyme normally present in placenta, gonads, brain, adipose tissue, liver, muscle, and hair. It catalyses the conversion of androgens to oestrogens. During pregnancy, large quantities of DHEAS and $16 \alpha-$ DHEAS produced by the fetal and maternal adrenal glands are converted initially to androstenedione and $16 \alpha$-andostenedione, and thereafter to oestrogens by placental aromatase. This enzyme action may also protect a female fetus from virilisation in conditions of maternal androgen excess, such as congenital adrenal hyperplasia. ${ }^{12} \mathrm{FAD}$ is rare and results from point mutations in the CYP19 gene. ${ }^{13}{ }^{14}$ Only about $1 \%$ enzyme activity appears necessary to prevent virilisation from increased androgen substrate. Consequently, the abundance of placental aromatase activity demonstrated during the second affected pregnancy suggests that a female infant would not have been virilised at birth. Affected individuals develop skeletal abnormalities related to oestrogen deficiency, and both male and female patients require oestrogen replacement. FAD was excluded in our patient by the normal cord androgens, the 


\section{Take home messages}

- We report a 28 year old woman with severe virilisation occurring in two successive pregnancies

- Recurrent maternal virilisation is rare-there are only seven previous reports - and this case is unique in its severity

- The differential diagnoses include ovarian disease and fetal aromatase deficiency (FAD)

- FAD was excluded and this case appears to be unique, with an ovarian origin that is not associated with an ovarian mass

- Although we were worried about the risk of fetal virilisation in a female baby, the normal placental aromatase activity and fetal androgen concentrations suggest that a female fetus would not have been affected

absence of low maternal oestrogen values, and the normal placental aromatase activity.

Placental sulfatase deficiency may result in raised androgen concentrations in pregnancy, but this enzyme deficiency results in decreased maternal oestrogen values and this was not seen our patient (fig 1). We also reported normal DHEAS concentrations, and these are usually low in sulfatase deficiency. Placental sulfatase deficiency does not lead to increased androgen concentrations of the nature seen in our patient. Furthermore, labour is often delayed in this disorder (both pregnancies were normal term), and there was no evidence of icthyosis, the typical skin lesion seen in sulfatase deficiency, in either infant.

In conclusion, there have been seven previous descriptions of recurrent maternal virilisation in pregnancy. Our patient is unique, however, because of the severity of her androgenisation and the dramatic resolution postnatally. We have excluded a fetal cause and believe that this represents a unique case with an ovarian origin that is not associated with an ovarian mass. We were concerned that if our patient had been pregnant with a female baby there would have been a risk of fetal virilisation; however, the normal placental aromatase activity and fetal androgen concentrations suggest that a female fetus would not have been affected.

\section{ACKNOWLEDGEMENTS}

We thank R Ward for technical assistance with the aromatase assay.

\section{Authors' affiliations}

H B Holt, S Medbak, D Kirk, R Guirgis, M H Cummings, D R Meeking,

Academic Department of Diabetes and Endocrinology, Portsmouth

Hospitals NHS Trust, Portsmouth PO6 3LY, UK

I Hughes, Department of Paediatrics, Addenbrookes Hospital,

Cambridge CB2 2QQ, UK

The patient gave her permission for this case report to be published

Correspondence to: Dr H Holt, Academic Department of Diabetes and Endocrinology, Portsmouth Hospitals NHS Trust, Portsmouth PO6 3LY, UK; hbholt@doctors.net.uk

Accepted for publication 2 August 2004

\section{REFERENCES}

1 Joshi R, Dunaif A. Ovarian disorders of pregnancy. Endocrinol Metab Clin North Am 1995;24:153-69.

2 Ben-Chetrit A, Greenblatt EM. Recurrent maternal virilization during pregnancy associated with polycystic ovarian syndrome: a case report and review of the literature. Hum Reprod 1995;10:3057-60.

3 Lowry OH, Rosebrough NJ, Farr AL, et al. Protein measurement with the Folin phenol reagent. J Biol Chem 1951;193:265-75.

4 Stillman SC, Evans BAJ, Hughes IA. Aromatase activity in genital skin fibroblasts from normal and androgen-insensitive individuals. J Endocrinol 1990; 127:177-83.

5 Hensleigh PA, Woodruff JD. Differential maternal-fetal response to androgenizing luteoma or hyperreactio luteinalis. Obstet Gynecol Sury 1978:33:262-71.

6 Kerber IJ, Bell JS, Camacho AM, et al. Luteoma of pregnancy: recurrent or persistent? South Med J 1969;62:1343-8.

7 Thomas E, Mestman J, Henneman C, et al. Bilateral luteomas of pregnancy with virilization. A case report. Obstet Gynecol 1972;39:577-84.

8 Shortle BE, Warren MP, Tsin D. Recurrent androgenicity in pregnancy: a case report and literature review. Obstet Gynecol 1987;70:462-6.

9 VanSlooten AJ, Rechner SF, Dodds WG. Recurrent maternal virilization during pregnancy caused by benign androgen-producing ovarian lesions. Am J Obstet Gynecol 1992;167:1342-3.

10 Bachman R, Gennser G, Hokfelt B, et al. Steroid studies in a case of ovarian hyperluteinization with virilism in two consecutive pregnancies. Acta Endocrinol 1974;76:747-64.

11 Morishima A, Grumbach MM, Simpson ER, et al. Aromatase deficiency in male and female siblings caused by a novel mutation and the physiological role of estrogens. J Clin Endocrinol Metab 1995;80:3689-98.

12 Lo JC, Schwitzgebel VM, Tyrrell JB, et al. Normal female infants born of mothers with classic congenital adrenal hyperplasia due to 21 -hydroxylase deficiency. J Clin Endocrinol Metab 1999:84:930-6.

13 Meinhardt U, Mullis PE. The aromatase cytochrome P-450 and its clinical impact. Horm Res 2002;57: 1 45-52.

14 Mullis PE, Yoshimura N, Kuhlmann B, et al. Aromatase deficiency in a female who is compound heterozygote for two new point mutations in the P450arom gene: impact of estrogens on hypergonadotropic hypogonadism, multicystic ovaries, and bone densitometry in childhood. J Clin Endocrinol Metab 1997;82:1739-45. 